\title{
UN ORIGINAL ANTECEDENTE DE "EL DESIERTO DE LOS LACANDONES" DE JUAN BALlinas, 1878
}

\author{
Víctor Manuel Esponda Jimeno
}

$\mathrm{E}$ n 1950 el Ateneo chiapaneco publicó las memorias de las exploraciones que llevó a cabo Juan Ballinas durante 1876-1877 por el "desierto de los Lacandones" o de "la Soledad". La edición de este preciado documento fue posible merced a los buenos oficios de Frans Blom y Gertrude Duby, quienes en uno de sus numerosos viajes por aquellas, entonces, exuberantes regiones, pasaron por la finca El Paraíso, propiedad de los descendientes de la familia Ballinas; allí se les enseñó el preciado cuadernillo que guardaba celosamente las andanzas y exploraciones de don Juan por aquellas regiones ignotas. $\mathrm{Al}$ ver este documento los Blom se entusiasmaron y de inmediato solicitaron se les permitiera hacer una copia de tan valiosos testimonio, petición a la que accedieron gustosos los propietarios de la finca. Así Frans y Trudy transcribieron a mano en una libreta el contenido del cuadernillo que consigna las andanzas del intrépido Ballinas y de su socio — después cuñado- Manuel José Martínez. La versión de los Blom de dicho documento fue después trasladada a máquina, Frans la revisó, anotó y agregó dos mapas y una nota introductoria en la que da cuenta del hallazgo resaltando su importancia y original contenido. La referida versión

Víctor Manuel Esponda Jimeno, Centro de Estudios Superiores de México y Centroamérica, unicach. la puso a consideración de los miembros del Ateneo susodicho, la cual fue acogida con agrado y enviada pronto a la imprenta, haciéndose un tiraje modesto de 800 ejemplares que pronto se agotó. Por ello, esta obra se convirtió en una pieza de colección. Años después, 1989, Rodrigo Núñez hizo una reimpresión facsímil, también de tiraje limitado, 950 ejemplares, que al igual que la primera pronto se agotó. Tal ha sido la demanda de esa obra que en 1998 el gobierno chiapaneco a través del Consejo Estatal para la Cultura y las Artes en coedición con la Asociación Cultural Na Bolom imprimieron el mencionado libro, en formato diferente de sus predecesoras ediciones, acompañado de una Introducción de Roberto Albores y un Liminar de Mario Uvence, gobernador del Estado y director del Consejo mencionado, respectivamente.

Dadas las sucesivas impresiones de la obra mencionada, las memorias de Ballinas pueden considerarse como una lectura obligatoria para aquellos que se interesen en la historia y literatura de la Selva Lacandona. Quizá Juan Ballinas fue el primer "coleto" que dejó testimonio de sus experiencias y vivencias en sus originales viajes por aquellas remotas y exuberantes regiones, y no hay duda que su obra ocupa un destacado lugar dentro del género "de las grandes exploraciones", haciéndose doblemente meritoria por tratarse de las 
memorias de un chiapaneco, pues la mayoría de estas obras han sido escritas por extranjeros que al confrontarse con la "otredad" todo les parece exótico y maravilloso. Desde luego que a Ballinas y Martínez les impresionó la exuberancia y riqueza de la selva chiapaneca, sobre todo por su generosidad en flora, fauna y abundancia de ríos, mas su objetivo estaba motivado por el utilitarismo, es decir, la explotación de las numerosas maderas finas, y por consecuencia el hallazgo de rutas acuíferas, expeditas y seguras que permitieran el traslado de las trozas a los lugares de comercialización.

La Selva Lacandona siempre ha llamado la atención de propios y extraños, en tal virtud la literatura al respecto es copiosa y variada. Desde el establecimiento de los castellanos en tierra chiapaneca se destinaron recursos para explorar y someter a aquella zona que desde un principio se consideró "tierra de guerra" y de frontera, a más de dilatada y de gran abundancia. Los intentos y empresas para someterla fueron numerosos, sus resultados insignificantes. Fue hasta finales del siglo XIX en que con mayores recursos y tecnología dicha región fue "conquistándose" por los madereros y después por los chicleros quienes sirvieron de avanzada para las ulteriores colonizaciones, invasiones y destrucciones del hoy "protegido" espacio selvático.

La Selva Lacandona, por su sólo nombre ha atraído poderosamente el interés de profesionales y profanos, de ahí que los materiales que a ella se refieren sean más de lo que queda de selva y en consecuencia también de lacandones, que dicho sea de paso, es el único grupo indígena selvático que existe en México. Por habitar en dicho espacio se le han atribuido mil fantasías y misterios: "buenos salvajes", "antropófagos", "arqueología viviente", "auténticos descendientes de los mayas clásicos", "comunismo primitivo", etcétera. La jungla mencionada, y todo lo que ella implica, desde las perspectivas histórica, ecológica, sociológica y humanística, es motivo propicio para aventurar mil reflexiones y elucubraciones, sin duda hay razones justas para ello, no obstante la realidad en su verdadera dimensión y en las actuales condiciones ofrece un panorama diferente y preocupante.

Hasta antes de la publicación del Desierto de los Lacandones se tenía por cierto que Ballinas y su obra eran casi desconocidos y que no había antecedente de sus memorias, por el contrario, la obra de su cuñado y socio se había difundido con anticipación, primero dada a conocer por el Ilustrísimo Señor Obispo Orozco y Jiménez en 1911, en el tomo II de sus Documentos inéditos relativos a la iglesia de Chiapas, ${ }^{1} \mathrm{y}$ años después Jan de Vos lo reprodujo en su antología Viajes por el desierto de la Soledad. ${ }^{2}$ Cabe decir que el documento escrito por Martínez es complementario a las memorias del señor Ballinas, el cual, como sugerí hace años, debe ser incluido como apéndice en las reediciones que se hicieren del Desierto. ${ }^{3}$

Poco es lo que se sabe acerca de la vida de Ballinas; monseñor Eduardo Flores Ruiz ${ }^{4}$ y Octavio Gordillo y Ortiz $z^{5}$ le dedican unas líneas generales resaltando su hazaña y descubrimientos. Realmente escasos son los datos que se tienen de este intrépido explorador que nació en San Cristóbal Las Casas el 24 de junio de 1841 y a quien pusieron por nombre Juan Bautista, hijo de don José María Ballinas y de doña Nazaria Estrada Guillén. Fue bautizado en la Santa Iglesia Catedral el 26 de junio del propio año, siendo su madrina doña Paulina Román. ${ }^{6}$

Se conoce que sus primeros años los pasó en el seno familiar primero recibiendo instrucción básica y luego ayudando a su padre en las labores agrícolas y en el oficio de carpintero. En 1869 contrajo matrimonio con la señorita Aurelia Penagos, ${ }^{7}$ luego se trasladó a la zona de Ocosingo donde estableció su finca, El Paraíso, y su familia. Una de sus hermanas, doña Graciana Ballinas, casó con Manuel de Jesús Martínez Gutiérrez, quien primero fue su socio en la empresa exploratoria 
del río Jataté por encargo de los señores Marcial Gutiérrez y Nicolás Valenzuela. Con Martínez emprendió la gran aventura que se narra en las memorias e informe que enseguida se reproduce. Dicho informe fue presentado el 18 de febrero de 1878 ante la Secretaría del Gobierno Constitucional del Estado Libre y Soberano de Chiapas con la finalidad de reclamar derechos y privilegios sobre las rutas y zonas madereras descubiertas por los susodichos, así como para obtener la gracia de concesión por los cinco viajes que emprendió por el desierto tantas veces mencionado. Para concluires preciso señalar que Ballinas se vio involucrado en problemas fiscales y mercantiles, por lo que en la resolución de esos penosos asuntos invirtió buen tiempo y dinero. Juan Bautista falleció en su finca el 23 de junio de 1905.

\section{Informe del reconocimiento de la nueva vía de comunicación con la República de Guatemala $^{8}$}

\section{Juan Bautista Ballinas}

Secretaría del Gobierno Constitucional del Estado Libre y Soberano de Chiapas.

En debida respuesta al oficio que con fecha 11 de Enero último, se sirvió ud. dirigirme pidiéndome informe sobre el reconocimiento que hice de la nueva vía de comunicación con la república de Guatemala, paso á rendirle en los términos siguientes:

Cinco incursiones emprendí al desierto, con el fín de proporcionar al Estado una nueva vía de comunicación con la ciudad de Flores, Yucatán y Belice, todas provechosas, porque en cada una hice un largo viaje, hasta alcanzar mi propósito, sin haber ocurrido más novedad que una víctima en dicho desierto, y como resultado de tan penosa expedición, la enfermedad de mi socio, que hasta hoy se encuentra en Huehuetenango (Guatemala) sin poder regresar á su domicilio.

En la cuarta vez que penetré en aquellos lugares, después de atravesar una sierra, andando en la planicie, observé que el río Jataté era navegable, mucho más, cuando á medio desierto, ví á dos lacandones que navegaban, siguiendo la corriente que me servía de guía. Con estos precedentes, el día 3 de Mayo último que ingresé a mi finca, pensé en mi quinta expedición, y para llevarla á efecto, comuniqué mi pensamiento á los ciudadanos Nemecio Pascacio, Nicolás Pérez y Manuel Martínez, quienes impulsados de un verdadero patriotismo, resolvieron prestarme su cooperación personal y pecuniaria para realizar una empresa que tantas ventajas había de producir al Estado. En el mes de junio el actual Gobernador C. Sebastián Escobar me honró, confiándome el descubrimiento del indicado camino, cuya comisión acepté gustoso, así para alcanzar el objetivo de mis aspiraciones, como por corresponder á la confianza que en mí depositaba el nuevo jefe del Estado, que al ascender al poder, ya pensaba en tan importantes negocios.

El río Jataté tiene su origen en la sierra de su nombre y cerro de Ispitín, que se halla al Sur, del pueblo de San Martín; continúa su curso al Este, reuniéndosele varios ríos y arroyos hasta pasar al Sur de Ocosingo. Desde este punto, que dista una legua, y más cuando, al Este, del mismo Ocosingo, se une con el río grande. Entonces puede considerarse de cinco varas de profundidad, buenas sus corrientes y sin pendiente alguna. No obstante, á ocho leguas de distancia, hay una cascada que impide la navegación, dificultad que puede subsanarse con la apertura de un canal desde San Juan hasta El Paraíso, por el lado Norte, y cuya longitud puede ser de dos leguas; $y$ con la composición de unos pequeños tramos que son: El Torno del Carmen, Ojo de Agua y Soledad del Desierto. Desde allí continúa siendo navegable, pues tiene una profundidad como de diez metros y una longitud de treinta; cuyas dimensiones aumentan progresivamente hasta unirse con el de la Pasión en donde ya tiene más de veinte metros de profundidad y cerca de ochenta de longitud; en atención á que tanto por el lado del Sur, como del Norte, se le reúnen otros seis ríos denominados: Santa Cruz, Tzaconejá, Perlas, El Azul, Santo Domingo y Santa Eulalia.

El río Jataté de que me vengo ocupando, y que pasa al Sur de Ocosingo, distante una legua, lleva en su curso, desde que se reúne con el de Santa Cruz, al Sur Este, 
hasta unirse con el de la Pasión, midiendo una distancia como de sesenta leguas; en cuyo trayecto el río no tiene pendientes ni cascada alguna, porque sus corrientes son tan suaves y benignas, que apenas podrán tener un veinticinco por ciento de descenso; cuyo río parte todo el terreno incógnito, donde se hallan las tribus llamadas lacandonas.

Si este canal de que hablo no pudiera abrirse, entonces el trayecto que va de Ocosingo a San Luis, y de este punto a una cañada que forman dos cerros al Norte de dicho río, hasta llegar al punto de la Soledad del Desierto, hay veinte leguas. De Ocosingo hasta dicho punto se pude hacer un buen camino carretero, hasta la orilla del río, donde, como se ha dicho ya es navegable con canoas de gran calado, hasta el río de la Pasión, quedando así sanjada la dificultad.- Siguiendo la afluencia del río de la Pasión, con veintidós leguas, se llega al Pozo Real, de donde, por tierra, hay doce leguas á la ciudad de Flores, capital del Departamento del Petén, y sesenta á Yucatán, todo de buen camino muy bueno para Guatemala, y que del camino de la ciudad de Flores parte otro para Belice.

Del mismo punto donde se junta el río Jataté con el de la Pasión, siguiendo su confluencia, es navegable hasta las dieciocho leguas en que hay una catarata peligrosa, formada de dos ondulaciones que bajan de unos cerros situados por ambos lados del río; por el del Sur tiene una pequeña cañada que facilita la apertura de un canal como de cuatro leguas de distancia, hasta reunirlo con el cauce del mismo río cerca de Tenosique; entonces es navegable por buques hasta donde desemboca el Usumacinta porque desde dicho Tenosique ya se conoce con ese nombre.

En todo el terreno del desierto que atraviesa el río Jataté, y en una extensión de tan vasta, que tiene y se calcula de Sur á Norte, como de cien leguas, y de Oriente á Poniente sesenta, se encuentra bastante palo de caoba, cedro, guayacá, tovillo, copalchij, tampucidan, chicozapote, granadillo, palo de bálsamo, palo de goma elástica, vainilla, pita fina, abundante palo de cacao, palma de toda clase y otras muchas maderas finas. Así es el dicho desierto que encierra una riqueza asombrosa y fácil de explotarse por el río Jataté, previamente abriendo el pequeño trayecto del camino de Ocosingo ó Soledad del Desierto.

Con todo lo expuesto hasta aquí, creo haber dado informe que se ha servido pedirme, por orden del ciudadano Gobernador del Estado, a quien como ud., me honro en tributar atenciones de mi consideración y respeto.- Libertad en la Constitución. San Cristóbal Las Casas, Febrero 8 de 1878. Juan Bautista Ballinas. Hay una rúbrica.- AI Secretario General del Superior Gobierno del Estado.- Presente. Es copia.-San Cristóbal Las Casas, Febrero 20 de 1878.- Juan J. Ramírez.

\section{Notas}

${ }^{1}$ Existe una segunda edición de esta obra preparada y prologada por el suscrito, publicada en 1999 por el Gobierno del Estado de Chiapas a través del Consejo Estatal para la Cultura y las Artes, Tuxtla Gutiérrez.

2 "El Desierto de la Soledad (1878)", en Viajes al desierto de la Soledad, Cuando la Selva Lacandona aún era selva. 1988, pp. 8087. Secretaría de Educación Pública y Centro de Investigaciones y Estudios Superiores en Antropología Social. México. Esta obra fue reeditada en 2003 con el título Viajes al desierto de la Soledad: un retrato hablado de la Selva Lacandona. Miguel Ángel Porrúa-CIESAS.

${ }^{3}$ Para una exégesis de la obra de Ballinas véase Víctor Manuel Esponda J. "Las memorias de Juan Ballinas por el Desierto de la Soledad o Desierto de los Lacandones", Revista CIHMECH, número 5, 1995: 173-177. Centro de Investigaciones Humanísticas de Mesoamérica y el Estado de Chiapas, unAm. ${ }^{4}$ El Libro de Oro de San Cristóbal de Las Casas, 1976, p.118. Gobierno del Estado de Chiapas.

${ }^{5}$ Biobibliografía de los escritores del estado de Chiapas, tomo I, 1996, pp. 23-24. UNAM.

${ }^{6}$ Libro de Bautismos de San Cristóbal que comienza en el mes de Febrero del Año de 1840 a 1842, foxa 113, partida 545. Archivo Histórico Diocesano, San Cristóbal de Las Casas.

${ }^{7}$ Cf. Prudencio Moscoso Pastrana, La Tierra Lacandona, sus hombres y sus problemas, 1986, p.55 y ss. Corporación de Fomento de Chiapas, S.A. de C.V.

${ }^{8}$ Publicado en El Fronterizo chiapaneco, febrero 27, tomo II, número 8, 1878. Órgano del Gobierno Constitucional del Estado. Se respeta la ortografía del original. 